\title{
LA DISPUTA POR EL ACOSO EN LA ESFERA CIVIL: \#METOO Y UNE AUTRE PAROLE
}

\author{
The dispute over harassment in the civil sphere: \\ \#Metoo and the Une autre parole
}

Nelson Arteaga Botello ${ }^{1}$, Luz Angela Cardona Acuña ${ }^{2}$

Fecha de recepción: 25 de septiembre de 2019

Fecha de aceptación: 10 de enero de 2020

1- Nacionalidad: Mexicana. Grado: Doctorado en Sociología. Adscripcion: Facultad Latinoamericana de Ciencias Sociales (FLACSO-México). Correo electronico: arbnelson@yahoo.com; nelson.arteaga@flacso.edu.mx. ORCID: (D) http://orcid. org/0000-0002-2660-7877

2- Nacionalidad: Colombiana. Grado: Doctorado en Ciencias Sociales. Adscripcion: Visiting Researcher (nov/2019 Ago/2020) en el Center for Cultural Sociology de la Universidad de Yale. Miembro nivel Candidata del SNI. Correo electronico: luzangela.cardona@gmail.com. ORCID: (D) http://orcid.org/0000-0001-8173-7466 


\section{Resumen}

Se analiza la disputa de sentido que generaron los posicionamientos encontrados del "\#Metoo" y la "Otra palabra" en torno al acoso y su sanción en la prensa iberoamericana, europea y estadounidense. Se examinaron los discursos en competencia que legitimaron y contaminaron las pretensiones de ambos posicionamientos. Se usó la metodología propuesta por la teoría de la esfera civil. Se analizó cómo se imputaron o atribuyeron motivos, relaciones e instituciones civiles y anti-civiles tanto al "\#Metoo" y la "Otra palabra". Se concluyó que los discursos en competencia definieron la legitimidad de estos posicionamientos a partir de los binarios de clase, raza, activismo político, posición moral, agresión y la centralidad de lo femenino.

Palabras clave: Competencia iscursiva; Acoso; \#Metoo; Une autre parole; Esfera civil.

\section{Abstract}

The dispute of meaning generated by the found positions of "\#Metoo" and "Une autre parole" about harassment and its sanction in the Latin American, European, and American press is analyzed. The competing speeches that legitimized and contaminated the claims of both positions were examined. The methodology proposed by the civil sphere theory was used. It was analyzed how civil and anti-civil motives, relations, and institutions were imputed or attributed to both the "\#Metoo" and the "Other word". It was concluded that competing speeches defined the legitimacy of these positions based on class binaries, race, political activism, moral position, aggression, and the centrality of the feminine.

Keywords: Discursive competition; Harassment; \#Metoo; Une autre parole; Civil sphere. 


\section{Introducción}

$\mathrm{E}$ n octubre de 2017 la actriz Alyssa Milano denunció el acoso sexual que sufrió del cineasta Harvey Weistein. "Si todas las mujeres que han sido acosadas o agredidas sexualmente -advertía- hicieran un tuit con el \#Metoo, podríamos mostrar a la gente la magnitud del problema” (D’Zurilla, 2017). Al día siguiente el \#Metoo fue tuiteado más de medio millón de veces y en Facebook fue usado por 4.7 millones de personas (Ohlheiser, 2017). Actrices, académicas y activistas respaldaron el hashtag (Ushma, 2017; Cadei, 2017) y se desató una oleada de denuncias por acoso en redes sociales en Estados Unidos, Europa, Asía, África y América Latina. Mientras en ciertos países reforzó los movimientos antiacoso, en otros se le acusó de ser un movimiento desestabilizador (Hasunuma y Ki-young, 2019).

En este contexto, un grupo de actrices estadounidenses organizó el colectivo Times Up, para crear un fondo de ayuda a mujeres víctimas de acoso. En la entrega de los Globos de Oro en 2018, actores y actrices apoyaron públicamente la propuesta. Oprah Winfrey dio un emotivo discurso en dicha ceremonia donde llamó a denunciar a los acosadores y respaldar a las mujeres "empoderadas" que habían contado sus historias de acoso. Para Oprah muchas mujeres viven bajo la opresión de hombres poderosos, pero su "tiempo se acabó" y en el futuro no habrá quien tenga que decir "yo también" (La Nación, 2018). El discurso fue respaldado por movimientos antiacoso como BalanceTonPorc en Francia, \#QuellaVoltaChe en Italia y \#YoTambién en España y América Latina.

El mensaje fue desacreditado también por un grupo de actrices francesas en una carta publicada en Le Monde, titulada Une autre parole: Des femmes libèrent une autre parole. En la carta se decía que el caso Weinstein, el movimiento \#Metoo y el discurso de Oprah, evidenciaron la violencia que sufren las mujeres en diferentes ámbitos. Pero cuestionaron que la denuncia en redes y prensa propiciaba una justicia expedita que produce sus víctimas: hombres que se ven obligados a renunciar porque se equivocaron "al tocar una rodilla, tratar de robar un beso, hablar sobre cosas íntimas en una cena de negocios, o enviar mensajes sexualmente explícitos" frente a una mujer que no se sentía atraída por ellos. De acuerdo con el texto de la Autre Parole (Infobae, 2018), con estas denuncias se envía a los hombres al "matadero social" y no ayudan a que las mujeres se empoderen, sirve a los "enemigos de la libertad sexual", "los extremistas religiosos", los "peores reaccionarios que defienden una concepción del bien y una moral victoriana, donde las mujeres son niñas con cara de adulto", “eternas víctimas de los hombres". La Autre Parole llamó a defender "la libertad de importunar", al ser indispensable para "la libertad sexual". "Una mujer puede -según el manifiesto francés- dirigir un equipo profesional y ser el objeto sexual de un hombre, sin ser una 'puta' ni una vil cómplice del patriarcado". Para esta posición "las mujeres no pueden traumatizarse por siempre después de un manoseo". Hay que enseñar a las niñas -se sugiere en la carta- que el acoso sobre el cuerpo no compromete su dignidad y no debe convertirlas en una "víctima perpetua", porque las mujeres no son reductibles a su cuerpo (Infobae, 2018).

El artículo examina el debate a escala global que generaron los posicionamientos del \#Metoo y la Otra palabra, en torno a las demandas de sanción, resarcimiento y desagravio a través de la comunicación, la regulación, la restructuración de instituciones y la reforma legal, es decir, de reparación civil (Alexander, 2006; 2013). Este debate se caracterizó por discursos en competencia que buscaron legitimar y contaminar las 
pretensiones de ambas demandas. ${ }^{3}$ Siguiendo la propuesta de la esfera civil, se argumenta que los discursos en competencia se construyeron a partir de códigos binarios que proporcionaron las categorías estructuradas para calificar los posicionamientos como puros o impuros (Alexander, 2006). Quienes apoyaron al \#Metoo y la Otra palabra se asumieron como referentes legítimos de evaluaciones normativas y morales que les permitieron juzgarse a sí mismas como racionales, inteligentes, informadas, autónomas y críticas -en otras palabras, actores legítimamente civiles-, mientras que calificaron a sus oponentes como rracionales, ignorantes, desinformadas, heterónomas y autocomplacientes-es decir, como anticiviles-.

Los discursos tipificaron los posicionamientos como moralmente justificadas o no a partir de: i) las atribuciones sociales e históricas que se hicieron a sus representantes; ii) la forma en cómo evaluaron las capacidades liberadoras y opresivas de la sexualidad y iii) la forma en cómo definieron las situaciones de acoso o seducción. La tipificación se hizo a partir de los siguientes códigos binarios: la clase social (pobre/rica), raza (blanca/no blanca), temporalidad del activismo (antigua/nueva feminista), posición moral (puritana/libertaria), gravedad de la agresión (seducción/acoso), centralidad de lo femenino (espíritu/cuerpo). Los discursos en competencia definieron una disputa simbólica con relación a la reparación civil por actos de violencia y acoso hacia las mujeres, así como interpretaciones diferenciadas sobre sus derechos, la igualdad y la equidad de género. El artículo revisa primero los conceptos básicos para examinar el debate como una disputa sobre el sentido del acoso y los mecanismos de reparación civil a favor de las mujeres. A continuación, se analizan las imputaciones sobre los motivos, las relaciones y las instituciones que permiten clasificar como civil y anticivil cada posicionamiento. Finalmente, se examinan los códigos en disputa entre \#Metoo y la Otra palabra.

\section{La esfera civil: entre la crítica y la integración social}

La esfera civil se entiende como un mundo de valores e instituciones que produce al mismo tiempo la capacidad de crítica y la integración social (Alexander, 2006: 22). Es una esfera de solidaridad y sentimientos hacia otros, que logra concebir culturalmente un cierto tipo de comunidad universalizante que suele traducirse en instituciones (Alexander y Tognato, 2018: 1). Estas últimas, junto con los valores movilizados en la esfera civil, producen una solidaridad distinta a la de las esferas de la economía, la familia, la religión y el Estado (Alexander, 2015: 174). Sin embargo, los compromisos de solidaridad no se cumplen nunca plenamente, debido a que hay un constante cuestionamiento sobre la capacidad de integración y exclusión de la sociedad, por lo que siempre hay interpretaciones críticas que buscan ampliar las bases de la inclusión a través de reparaciones civiles.

Estas demandas críticas o de cambio las llevan a cabo movimientos sociales o culturales (Alexander, 2006: 213, Eyerman y Jamison, 1990: 120). Frente a las cuales hay una respuesta en contra que busca mantener la interpretación normalizada de las formas de solidaridad y sus instituciones, para garantizar

3- El artículo no es un análisis desde la perspectiva de género, el feminismo, la disputa entre cultura francesa o estadounidense, ni desde los movimientos sociales, perspectivas que no estudian ni están interesadas en analizar cómo es interpretada la acción de los movimientos sociales en una esfera civil ampliada. Para una análisis desde estas perspectivas ver: McKinney (2019), Downing (2018), Banet-Weiser, Gill y Rottenberg (2019), De Benedictis, Orgad y Rottenberg (2019), Lamas (2018), Di Bennardo (2019), Grenier (2019), Johansson y Scaramuzzino (2019), Hasunuma y Ki-young (2019), Mendes, Keller y Ringrose (2019), Pfister y Yang (2018), Clark-Parsons (2019). 
la permanencia del orden social y niegan cualquier tipo de reparación civil. Estas disputas se dirimen en la esfera civil a través discursos en los que mutuamente se califican a los actores que participan en ellas como puros o impuros (Douglas, 1979: 74), legítimos o ilegítimos, que merecen ser incluidos o excluidos del debate público o, más aún, de la sociedad (Alexander, 2006: 54-55). En las sociedades democráticas estas atribuciones se hacen por medio de un código civil que permite a ciertos actores asumirse como miembros con virtudes cívicas -autónomos, responsables, racionales- y juzgar a los otros como condensaciones del vicio cívico -heterónomos, irresponsables, no racionales. La calificación e identificación con lo puro y lo impuro es determinante para la concreción del sentimiento de solidaridad, la apatía, la descripción y la prescripción propios de la esfera civil.

Tal es el caso de los movimientos feministas que han buscado transformar las estructuras de dominación impuestos por el sistema heteropatriarcal, mismo que se sostiene en valores y principios no civiles anclados en una forma específica de modelo de familia, por ejemplo (Alexander, 2017: 127). La movilización feminista, ha generado una presión a favor de la igualdad de género y mecanismos de reparación civil frente a las lógicas de dominación, discriminación y violencia contra las mujeres (Luengo, 2018: 39); es decir, a reescribir la relación entre los valores universales y los valores particularistas de inclusión y solidaridad social. Ante la acción de las feministas, se han generado reacciones que consideran que estas demandas apuntan a afectar valores considerados como esenciales para la vida en sociedad, tales como la familia tradicional, roles asignados "naturalmente" a hombres y mujeres, así como un conjunto de principios morales no civiles que garantizan aparentemente la cohesión y la solidaridad social. En el caso que aquí se analiza encontramos una paradoja porque los discursos en disputa que se examinan apelan a valores civiles y feministas. ${ }^{4}$

El código civil permite a los actores sociales la construcción de discursos binarios en tres niveles: el de los motivos, las relaciones y las instituciones (Alexander, 2006: 57-59). En el nivel de los motivos, se analiza el nivel de autonomía o dependencia que se imputa a los actores. En las relaciones, se valora qué tan transparentes o no son los vínculos que tiene y a los que aspiran. En el de las instituciones, se juzga hasta qué punto normas y reglas orientan o no la acción, "si son incluyentes e impersonales, o por el contrario predomina el uso discrecional del poder, las lógicas de exclusión y las relaciones personales" (Arzuaga y Arteaga, 2017: 155).

"La esfera civil es un emplazamiento organizado de patrones simbólicos que, de manera diferencial, se comprenden e interpretan significativamente por los actores. Es un espacio cultural, pero también institucional" (Arzuaga y Arteaga, 2017: 155). Las instituciones de la esfera civil transforman las categorías de lo civil y anticivil en relaciones sociales concretas, en marcos normativos y estructuras institucionales. Hacen posible que se articulen demandas sociales de inclusión, exclusión, integración y represión. Para esta teoría existen dos tipos de instituciones: comunicativas y regulativas. Siguiendo a Kivisto y Sciortino (2015: 18), las primeras son aquellas que reflejan y difunden las posturas, pasiones e intereses de la membresía universalista, la red de actores legitimados que hablan "en nombre de" el público, al público,

4- Si bien hay teorías que pudieran complementar esta perspectiva, no se desarrollan aquí porque enfatizan otros procesos. Nancy Fraser (1992), por ejemplo, considera que los movimientos feministas se definen por procesos de identidad, dejando de lado que se construyen refractando las representaciones universales de la esfera civil. De igual forma el trabajo de Seyla Benhabib (1992) solo se centra en los círculos de socialización primarios y secundarios. Mientras que Carole Pateman (1988), parte del supuesto de que los valores de la esfera civil se equiparan a los valores patriarcales. 
como el público. Incluyen los medios de comunicación, la opinión pública y las asociaciones civiles. Las segundas, son aquellas que obtienen su derecho a tomar decisiones vinculantes a partir de su reclamo de actuar en nombre de dicha solidaridad: cargos por elección y tribunales. Ambas son necesarias para cristalizar la solidaridad y garantizar la concreción de las narrativas civiles.

Los discursos en competencia en torno al \#Metoo y la Otra palabra pueden analizarse como una disputa que movilizó el código civil en las instituciones comunicativas de la esfera civil. Este permite establecer cómo se clasifican las interpretaciones sobre el sentido del acoso sexual contra las mujeres y su reparación. Las imputaciones que marcan a las representantes del \#Metoo y la Otra palabra permitieron a quienes las apoyan y critican justificar el porqué defienden o cuestionan la libertad de importunar, la libertad sexual, la denuncia de acosadores en redes sociales y el control de la pulsión sexual. El debate discutió cómo deben definirse las relaciones entre los sexos, la individualidad, el ejercicio de la justicia y la reparación civil de las víctimas.

Siguiendo la propuesta metodológica de la teoría de la esfera civil, se analizó la construcción del debate en las instituciones comunicativas, particularmente la prensa de ciertos países de Iberoamérica (Argentina, Colombia, Ecuador, España, México y Perú), Francia, Estados Unidos e Inglaterra. Se revisaron 475 columnas publicadas entre el 9 de enero y el 27 de marzo de 2018, período en el que se mantuvo activo el debate en medios. ${ }^{5}$ Las notas periodísticas contienen información sobre los eventos (Río, 2008: 59). A efectos de contar con un marco de interpretación lo más plausible posible se compararon las interpretaciones de diferentes fuentes y líneas editoriales, considerando que la crónica periodística es una interpretación sobre un acontecimiento (Ortiz, et al, 2005: 406; McCarthy, et al, 1996: 479). Se reconoce que las columnas periodísticas son parciales y sesgadas en las interpretaciones que ofrecen, porque se construyen en marcos de interpretación anclados en referentes morales específicos (Earl, et al, 2004: 67; Río, 2008: 60).

El sesgo de los medios de comunicación es una fuente para analizar cómo las interpretaciones activan la discusión en la esfera civil. Como sugieren Alexander (2016: 14) y Butler y Luengo (2016: 284), los medios de comunicación construyen mensajes que traducen situaciones concretas en códigos civiles universales a través de evaluaciones y narraciones, al tiempo que -siguiendo a Gupta (2015: 193) - sus discursos narrativizan la vida cotidiana e imaginan colectividades. Posteriormente se procedió a identificar y sistematizar en matrices los códigos en disputa, las tipificaciones, juicios y categorizaciones sobre las representantes de los dos movimientos en el nivel de los motivos, las relaciones y las instituciones. ${ }^{6}$

5- Las palabras clave de la búsqueda fueron los nombres de los dos movimientos en Google, Google Scholar y Proquest y en los periódicos de mayor circulación de los países analizados. Cada una de las referencias periodísticas se analizó ubicando qué tipo de motivos, relaciones e instituciones se imputaban tanto a \#Metoo y la Otra palabra. Primero, se tomó registró si cada posición era considerada como la expresión racional, razonable, realista y objetiva -un acto de agencia- o por el contrario irracional, prejuiciosa, irrealista y subjetiva -un acto sometido a las estructuras normativas de dominación-. Segundo, se tomó registro de si cada posición era evaluada como la expresión de mujeres insertas en relaciones abiertas, críticas y francas -es decir plenas de virtudes civiles-, o cerradas, discrecionales y orientadas a beneficiar a un sector de la población -es decir, hombres o mujeres-. Tercero, se registró el tipo de instituciones que supuestamente defendían: reguladas, bajo el imperio de la ley, equitativas e inclusivas o, por el contrario, arbitrarias, discrecionales, jerárquicas y excluyentes.

6- No se consideró como criterio de análisis la cantidad de hombres y mujeres en el debate, ya que los discursos en disputa fueron activados por ambos sexos. 


\section{Las imputaciones anti-civiles a la Otra palabra}

En las columnas de opinión se acusó al manifiesto francés de: i) buscar fracturar el movimiento feminista y enfrentar a las mujeres; ii) ser incapaces de ver las condiciones reales de vida de las mujeres; iii) ocultar el carácter contaminado de las relaciones entre hombres y mujeres -reproduciendo las asimetrías de poder y dominación, garantizando la permanencia de la cultura patriarcal-; y iv) obstruir el trabajo de las instituciones diseñadas para frenar la violencia, demandando a las mujeres que antes de denunciar reflexionen sí estuvieron realmente frente a una situación de acoso o un acto torpe de galantería.

\subsection{Motivos}

El manifiesto francés fue interpretado como la expresión de mujeres incapaces de entender los cambios en los códigos que pautan la relación entre hombres y mujeres. Como señaló Dubois citada por Peker (2018), las intelectuales, empresarias y periodistas francesas que firmaron el manifiesto detienen su inteligencia para no pisar una cancha donde no saben jugar. Un terreno desconocido donde tendrían que reinventar los códigos que dieron fundamento a sus vidas exitosas. Es un manifiesto occidental y blanco (Adler en Lehoux, 2018), que minimizó la situación de las mujeres a nivel mundial (Beltrán, 2018; Latapí, 2018; Collado, 2018; Dunham, 2017). A decir de Kislinger (2018), es producto del resquemor y la confusión, excesivo si se toma en consideración que el acoso es considerado 'natural' en nuestra sociedad.

En segundo lugar, se acusó que sus firmantes provienen de grupos privilegiados. Es el discurso de mujeres que viven en un contexto social privilegiado que defienden 'el derecho a importunar' minimizando la experiencia de aquellas que han vivido el acoso (Collado, 2018) y la ruptura cultural que ha introducido el \#Metoo (Gersen, 2017). El manifiesto expresó la "contrarrevolución de las privilegiadas contra las desposeídas" (Merino, 2018; Olavarría, 2018). Como sugiere un grupo de feministas encabezado por Caroline de Haas, la Otra palabra denuncia el sexismo machista cuando emana de hombres de barrios populares, "pero dejan la mano en el culo" cuando se ejerce por hombres de su mismo medio social. Esta extraña ambivalencia, sugieren, permite apreciar el feminismo que defienden (France Télévisions, 2018). La falla central de la Otra palabra estriba -según Lamas (en Milenio, 2018)- en no conocer las diferencias que implica denunciar el acoso cuando se es una actriz europea o norteamericana, de cuando se es obrera, empleada del hogar, campesina, oficinista o secretaria.

Las críticas advirtieron el carácter clasista del manifiesto, que no tiene cabida cuando se trata de respetar la dignidad de las mujeres (Amo García, 2018; Europa Press, 2018; De Hass en Mascia, 2018; Thomas, 2018). Quienes suscribieron dicho documento son mujeres "sordas, ciegas, que viven en un "París-blanco-entre-muros" (Priego-Broca, 2018). Esto les impide ver -a decir de De Anda (en Lucario, 2018f)- más allá de sus narices, no reconocen el privilegio que implica no tomarse a mal un tocamiento o una insinuación sexual. En este sentido, la Otra palabra fue considerada el reflejo -como dejó ver por ejemplo García (2018a) - de la trivialización, la banalización y el vaciamiento de significados sobre lo qué es el feminismo. Esta opinión la comparte, también, Dresser (2018) y Bernal-Triviño (2018), quienes calificaron el manifiesto como un acto trivial, de lenguaje insensible, reduccionista, cuyas autoras parecen estar dispuestas a perdonarlo todo. 
En tercer lugar, el manifiesto fue calificado de ambivalente, al defender el derecho a importunar en materia sexual (Cruz, 2018). Para algunas analistas, las francesas encabezadas por Deneuve y Millet, asumen que todas las mujeres podrían decir no a una insinuación sexual, sin considerar sus características socioeconómicas o culturales (Torreblanca et al, 2018). Peker (2018) advirtió que las firmantes del manifiesto "demostraron ser poco sensibles y empáticas ante el hartazgo de las generaciones más jóvenes que no están dispuestas a tolerar las reglas del juego establecidas y la falta de libertad que conllevan las prácticas y costumbres machistas". El posicionamiento de las francesas también fue catalogado como "terrorífico", al apoyar la naturalización de una práctica de la que han sido víctimas muchas mujeres (Díaz, 2018; Revuelta, 2018). Además de ser una respuesta de los "puercos y sus aliados que tienen razón de preocuparse porque las cosas están cambiando para ellos" (France Télévisions, 2018).

Según Wiener (2018a), "el manifiesto es una venganza del patriarcado, escrito por mujeres que actúan como cómplices de un sistema perverso". Un punto en el que coincide García (2018a), al afirmar que es una estrategia contra el avance de las mujeres jóvenes que se están rebelando contra la injusticia y aliándose con los feminismos. Como sugieren De Haas (en Mascia, 2018) y Munker (2018), para los "puercos y sus aliados, el viejo mundo está en vías de desaparecer, muy lentamente, pero inexorablemente" (France Télévisions, 2018).

En algunas columnas se juzgó que las francesas solo buscaron llamar la atención frente a las actrices detrás del \#Metoo (Europa Press, 2018). Sus planteamientos fueron calificados como "voces disonantes" ante a los avances en materia de igualdad que busca el \#Metoo (Dumitru en La Voz de Galicia, 2018). Para Luciana Peker (2018) el documento impacta y duele porque viene de mujeres que seguramente sufrieron algún tipo de acoso. El manifiesto fue calificado como "un escrito absurdo" teniendo en cuenta lo que pretende el feminismo contra el acoso sexual. Las actrices que lo firmaron están equivocadas, según sus críticas, porque enfrentan a las mujeres contra otras mujeres. A decir de Ares (en Europa Press, 2018) y Sánchez-Mellado (2018), la publicación de las galas es inconveniente para este momento cuando las cosas pueden cambiar definitivamente. En este sentido fue desafortunada la forma y el momento en el que fue publicado (ver, Lamas en Milenio, 2018; Solórzano en Lucario, 2018b; Peker, 2018). Finalmente, algunas críticas señalaron que la posición de la Otra palabra debe entenderse a partir de la historia social e intelectual de Francia -como sugiere Amo García (2018)-, donde constantemente se cancelan los mecanismos de oportunidad hacia las mujeres. No debe sorprender, por ejemplo, que el manifiesto sea "un golpe que viene de una Francia cuna del feminismo, pero que posterior a 1789 negó los derechos políticos a las mujeres".

\subsection{Relaciones}

Los motivos anti-civiles atribuidos a la Otra palabra tienen su correlato en la imputación que se hace a las relaciones entre hombres y mujeres. Se señaló, en primer lugar, que la Otra palabra no contempla el hecho de que los hombres se aprovechan de su posición de poder para acosar (West, 2018); es decir, se dejan de lado las asimetrías de poder en las relaciones sexo/género (Lamas en Milenio, 2018; De Anda en Lucario, 2018f; Europa Press, 2018). Por eso la Otra palabra termina por justificar a los predadores (Félix, 2018; Gérard, 2018). Como sugieren Réjane Sénac (2018) y Casanova (2018), el manifiesto ignoró que la llamada "seducción a la francesa” oculta la asimetría entre los sexos y por alguna razón su desaparición las inquieta (Belaich, 2018). 
Las relaciones entre hombres y mujeres, afirma Catherie Achin (en Raulin, Mallaval y Bretton, 2018), están constituidas en Francia no en la igualdad, sino en la discriminación de los sexos (Belaich, 2018). Si los franceses son seductores, lo es siempre en masculino, no en femenino (Montreynaud, citada en Belaich, 2018).

En segundo lugar, se valoró que la Otra palabra pasó por alto las relaciones mujer-hombre en los espacios laborales, donde "un acostón, el manoseo o salidas" con el jefe son cosas comunes (Lamas en Milenio, 2018; Carlson, 2017). El error de las francesas fue incluir la idea de libertad sexual en el contexto laboral (Dumitru en La Voz de Galicia, 2018). Al decir que no hay que confundir acoso con una conducta torpe, las francesas tomaron, a decir de Salvador (2018), una actitud maternal con respecto a los hombres que justifica la acción de los estos últimos frente a mujeres que juegan "a la dama y el caballero" pero todavía no saben cómo hacerlo. La defensa de los hombres, como advierte Peker (2018), es innecesaria puesto que ellos no necesitan defensoras. Las actrices galas, a decir De Anda (en Lucario, 2018f) "no ven la diferencia entre los lugares de la seducción y la persona que es pretendida con igualdad o no de condiciones, eso marca la diferencia respecto de las consecuencias al negarse".

La Otra palabra omitió -según Lamas en Milenio (2018) y Hubbard (2017)- la violencia estructural detrás de las relaciones entre hombres y mujeres. En el mismo sentido, Salas (en Lucario, 2018c) señaló que cuando se habla de acoso u hostigamiento, se habla de ejercicio de poder, de dominación. Cuando un agresor cosifica a la mujer, abusa de su posición, esto no puede interpretarse como parte de la libertad sexual de los hombres. El hostigamiento es una herramienta que los hombres utilizan para condicionar el acceso a las mujeres al mundo laboral y económico. La Otra palabra dibujó una línea difusa entre la seducción y el acoso -advierten Amo García (2018) y Stephens (2017)-, dañando la credibilidad de las mujeres que lo denuncian. Al no separar el acoso y la libertad -señalaron (Cacho en Mural de Negro, 2018) y Berrin (2017) - las galas reivindican el poder machista sobre el cuerpo y la voluntad erótica de las mujeres.

Aunque el manifiesto de la Otra palabra sugirió que cualquier agresión corporal no debe socavar la integridad espiritual de las mujeres, no se puede ignorar -como apuntó Adler (en Lehoux, 2018) y Collins (2018)-, que cualquier ataque al cuerpo se traduce inmediata y consustancialmente en una agresión física. Cuando una mujer es agredida es porque es considerada como un objeto (Lehoux, 2018). Como apuntó Lévy-Willard (2018), las mujeres detrás de la Otra palabra ignoraron que los antropólogos explican que el control corporal de las mujeres tiene como función garantizar su servidumbre en las sociedades humanas. En conclusión, la posición de la Otra palabra -sugiere De Anda (en Lucario, 2018f) - no es capaz de distinguir la seducción y la galantería del acoso y violencia contra la mujer, reproduciendo las ideas tradicionales que hay sobre el amor y el sexo (Ruiz-Navarro en Milenio, 2018). Deberíamos cuestionarnos -sugieren De Anda (en Lucario, 2018f) y Wiener (2018b)cómo la Otra palabra llegó a sugerirnos que es necesario defender a los hombres acosadores y culpar a las mujeres que han sido acosadas.

\subsection{Instituciones}

Las críticas al manifiesto consideran que la banalización del acoso como "coqueteo torpe" dificulta la operación de las instituciones que atienden y sancionan la violencia contra las mujeres. Su posición exige a las mujeres valorar su experiencia como poco importante o menos grave que otras vulneraciones a derechos 
(Coll, 2018, Filipovic, 2017). Para sus detractoras, el texto francés es una defensa de lo que el hombre desea: "perpetuar y solapar una cultura machista donde la desigualdad está presente" (Díaz, 2018). Otros críticos sugieren que la Otra palabra propone soportar el acoso cuando debería reflexionar en nuevas formas de relacionarnos romántica y sexualmente" (Torreblanca et al, 2018). Para Ruiz-Navarro (en Milenio, 2018), por ejemplo, la denuncia "rompe una alianza con los hombres que ha sido cómoda para mujeres que dicen que señalar el acoso es exagerar y por eso reciben validación de los varones a su alrededor".

Para Faur (2018) las francesas niegan el acoso y suman argumentos a uno de los mitos contemporáneos del género: el acoso es un invento para "joder" a los hombres. Así, la Otra palabra acaba por defender la libertad de "cualquier Harvey Weinstein" en el mundo. De igual forma ocultó, como apunta Adler (en Lehoux, 2018), el hecho de que existe en occidente una dominación masculina que se ejerce política, jurídica, sexual e intelectualmente. Se acusó a las firmantes francesas, de traicionar "la batalla cotidiana de miles de mujeres en el mundo contra el acoso sexual". De hecho -afirman Priego-Broca (2018), Solórzano (en Lucario, 2018b) y De la Peña (2018)- "declararse 'en respuesta a’ fue muy desafortunado" sobre todo en contraposición al \#Metoo. Incluso, el manifiesto falló en caricaturizar el puritanismo anglosajón como el principal enemigo a vencer cuando menos en dos sentidos. Primero, porque descontextualizan el puritanismo norteamericano (Cacho en Mural de Negro, 2018; Melgar, 2018); segundo porque -como advierte Carmen Boullosa en entrevista con Sandra Lucario (2018a)-, faltó que aportaran "un punto de vista alternativo sobre las intolerancias bifocales del puritanismo anglosajón".

A decir de Salas (en Lucario, 2018c), por ello una parte importante de feministas se ha desmarcado del manifiesto francés, no las representa y es valorada como una declaración de guerra contra el feminismo (Borrelli citada por Peker, 2018). La Otra palabra está abanderada por "mujeres que son reincidentes en materia de defensa de pedocriminales y de apología de la violación, [que utilizan] su visibilidad mediática para banalizar la violencia sexual [y] desprecian el hecho de que millones de mujeres sufran o hayan sufrido este tipo de violencia" (Wiener, 2018a). La Otra palabra se calificó como un texto "antifeminista" -como sugiere Regina Tamés (en Lucario, 2018e) y Cárdenas (en Wiener, 2018a)-, porque señala que el acoso es una cosa "confusa", cuando lo fundamental es el debate sobre el consentimiento. Sin embargo, para otras activistas francesas (Adler en Lehoux, 2018), el texto francés fracturó la solidaridad entre mujeres al introducir la idea de que algunas confunden el acoso con galantería.

\section{Las imputaciones civiles a la Otra palabra}

Los discursos que respaldaron la Otra palabra señalaron que: i) inspiran la defensa de la libertad y la pulsión sexual de mujeres y hombres -principios que forman parte de la historia y la cultura francesa-; ii) reconocen a la mujer en tanto agente erótico y no como un infante en permanente estado de victimización -esto garantiza que puedan construir relaciones equitativas con relación a los hombres-; iii) exigen abrir un debate social e institucional sobre el sentido del acoso, sobre las circunstancias espaciotemporales en el que se presenta, con el objetivo de aclarar malentendidos, garantizando con ello justicia y debido proceso, tanto para las víctimas como para los presuntos acosadores. 


\subsection{Motivos}

Quienes defendieron la Otra palabra señalaron que sus motivos fueron la defensa de la libertad sexual (Tamés en Lucario, 2018e; Faur, 2018; Fernández, 2018). Una reivindicación, a decir de Andión (en Lucario, 2018g), para no condenar ninguna sexualidad. El posicionamiento francés pugnó por integrar al debate el tema del consentimiento desde una perspectiva interseccional (Torreblanca et al, 2018; Ruiz-Navarro en Milenio, 2018). Es un posicionamiento directo sin mojigaterías, saludable y valiente (Reuters, 2018; González, 2018; Barbier en Mascia, 2018). Un documento que derribó el muro de lo políticamente correcto, dando voz a las feministas que piensan diferente el acoso (Sastre en Gérard, 2018; Aloma Rodríguez, 2018; Díaz, 2018). Rompió con los discursos únicos o condescendientes (Ferreyra, 2018; Morejón, 2018). A decir de Viennot (2018) el texto es una acción provocadora, argumentada e intelectualmente elaborada; una posición contra el ortofeminismo - un tipo único y hegemónico de feminismo que cierra la puerta a otros feminismos-. El texto pretende la reflexión y no la "cacería de brujas" (De Paz, 2018; Mascia, 2018). Quienes suscribieron Otra palabra fueron juzgadas en términos civiles: mujeres "valientes y provocadoras [que] denuncian un clima de sociedad totalitaria" (Nebot, 2018). Mujeres que han revelado las "reglas jodidas" que algunas actrices han aprovechado para hacer carrera (Lamas en Milenio, 2018).

La postura de las francesas reivindica -según Ayuso (2018), Cacho (en Mural de Negro, 2018) y Tagle (en Lucario, 2018d) - que la sexualidad es deliciosa e incita al juego, sin ser invasiva o desigual. La Otra palabra recordó que la censura y la moralidad ponen restricciones y normativizan la relación entre hombre y mujeres (Zárate, 2018). Este posicionamiento -advierten Ferreyra (2018), Marco, (2018) y Faur (2018) - no todo es violencia, hay deseo, amor, amistad y placer que no pueden someterse a mecanismos de regulación para estar a salvo de cualquier malentendido. La sexualidad está conformada de encuentros, desencuentros, aciertos y desaciertos, por lo que no se debe reprimir el flirteo o la seducción (Dumitru en La Voz de Galicia, 2018).

La seducción -señala Podirier (2018) - "es un juego inocuo y agradable, que se remonta a los tiempos del 'amor cortés' medieval [...] por eso siempre ha habido una especie de armonía entre los sexos que es particularmente francesa". La Otra palabra defiende el derecho de sorprender y ser sorprendidas (Salvador 2018; Nebot 2018). Como apunta Anne Morelli (en RTBF, 2018), \#Metoo deja de lado el hecho de que las mujeres también seducen, coquetean y acosan, por lo que no son siempre víctimas (Razer, 2018; Weiss, 2018; RTBF, 2018). La feminista Valérie Toranian (2018), señaló que el problema no está en el sexo, sino en el poder: este es el que crea el abuso, no el sexo. Siempre hay junto al hombre de poder, un seductor serial, de la misma manera que hay mujeres con poder que son seductoras seriales.

Quienes apoyaron la Otra palabra resaltaron la libertad sexual y de pensamiento, relativizando el significado del cuerpo en la vida de las mujeres. Las francesas defienden lo que pasa al cuerpo, pero no le dan tanta importancia, invitando a repensar qué tanto le cedemos al patriarcado su excesiva valoración del cuerpo en nuestra vida (Nebot 2018; Ferreyra 2018, Morelli en RTBF, 2018). Esto no significa que aquello que un hombre hace con el cuerpo de una mujer no sea grave, a decir de Viennot (2018) y Sastre (en Gérard, 2018), pero no puede marcar la vida de las mujeres.

A decir de Marco (2018) y Viennot (2018), la Otra palabra no defiende a los acosadores o el machismo, pero advierte que no son lo mismo los violadores y aquellos hombres que hacen tocamientos en 
el metro o la calle. La Otra palabra señala que no se pueden igualar las acciones de los productores de Hollywood y el acoso en el transporte público, porque entonces el acoso se vuelve un cajón donde caben todos los sufrimientos de las mujeres. El posicionamiento de las francesas se consideró la expresión de intelectuales con una vida sexual que no se ajusta a una agenda, mujeres capaces de aceptar un vibrador como presente de aniversario (Salvador, 2018). De esta forma, la Otra palabra fue valorada como la expresión de mujeres con motivos racionales y autónomos.

\subsection{Relaciones}

La Otra palabra se interpretó a partir del residuo histórico, social e intelectual de Francia. El manifiesto se asoció con reivindicaciones que databan del siglo XVIII: "algunos de los íconos son los salones de discusión, varios conceptos sobre libertad sexual. El feminismo no podría concebirse sin sus aportes. Su manifiesto no es de extrañar" (González, 2018). Quienes apoyaron a la Otra palabra vieron en las feministas francesas -como hace Salvador (2018)- la vanguardia de la liberación sexual del siglo XX, la cual tiene expresiones que van desde las orgías a las prácticas sadomasoquistas o la experimentación, así como cualquier tipo de atrevimiento sexual.

Para algunos comentaristas su feminismo resalta la diferencia: la posibilidad de una sexualidad al margen de la mirada patriarcal (Martínez, 2018; Cruz, 2018). Los defensores del manifiesto sugieren que las francesas no se reconocen en el feminismo que odia a los hombres (Podirier, 2018). Rechazan el puritanismo porque la literatura y la cultura francesa se caracterizan por el libertinaje, la galantería y la libertad sexual cristalizados en el Marqués de Sade, Michel Foucault o Choderlos de Laclos (Mascia, 2018; Dudda, 2018). El manifiesto es visto por sus defensores como el reflejo de una cultura más natural y más permisiva que entiende la sexualidad como parte integral de la vida (Estremadoiro, 2018).

La Otra palabra se comparó con el planteamiento de Simone De Beauvoir. Ésta advertía que las mujeres y los hombres estadounidenses actúan como si no se gustaran, incapaces de generar lazos de amistad. Entre ellos hay desconfianza y se relacionan a través de pequeños agravios y disputas (Podirier, 2018). No todas las mujeres, consideran Tamés (en Lucario, 2018e) y Morejón (2018), son víctimas, ni todos los hombres son agresores. No se puede condenar a las mujeres a su permanente infantilización (Podirier, 2018; Solórzano en Lucario, 2018b; Nebot, 2018; Atwood, 2018). Si la mujer posee agencia, la seducción es una relación de doble vía, una danza voluntaria entre dos (Cacho en Mural de Negro, 2018; Atwood, 2018). Para algunas comentaristas -como Ferreyra (2018)- las francesas invitaron a pensar si es verdad que los hombres manejan e imponen su deseo a las mujeres.

Para los partidarios de la Otra palabra la seducción reivindica la pulsión erótica masculina. No es condenando el deseo masculino sino compartiéndolo con las mujeres que ellas lograrán emanciparse (Mascia, 2018). Las actrices que respaldan el manifiesto francés han dado voz a los hombres frente al silencio o la aceptación sin defensa de quienes los acusan. Esto significa que los hombres no van por el mundo acosando mujeres (Lozada, 2018; Ferreyra, 2018). Incluso, como ha señalado Lamas (2018), y Merkin (2018) las mujeres usan su capital erótico para conseguir cosas y muy probablemente los hombres malinterpretan esos mensajes. 
La reivindicación de lo masculino sugiere que la superación del patriarcado no puede hacerse linchando al varón, renunciando a las conquistas de cuerpo y sexo, anulando las artes como catarsis, cometiendo la libertad creadora a las censuras más reaccionarias (Morejón, 2018, De la Barreda, 2018). La Otra palabra alienta a los hombres y mujeres a que pasen cosas -sexualmente hablando-, sin justificar la violencia, sino apostando por mujeres empoderadas, improvisadas y espontáneas (Ferreyra, 2018; Faur, 2018). Se interpretó el manifiesto-véase por ejemplo De la Peña (2018), Aloma Rodríguez (2018), Díaz (2018), González (2018), Torreblanca et al (2018)- como un llamado a frenar la histeria puritana en nombre de la dignidad de las mujeres. En consecuencia, fue calificado como una "resistencia al feminismo puritano" (Mascia, 2018; Tamés en Lucario 2018e; Andión en Lucario, 2018g; Martínez, 2018; Dumitru en La Voz de Galicia, 2018; Andrade, 2018).

\subsection{Instituciones}

La Otra palabra buscó que las instituciones encargadas de justicia pusieran por delante la presunción de inocencia y el debido proceso de los supuestos acosadores (Tamés en Lucario, 2018e; Atwood, 2018). Se calificó que la estrategia de denuncia en redes sociales de \#Metoo está siendo excesiva. Ser acusado de acoso implica ser juzgado como culpable (Merkin, 2018). La Otra palabra es un llamado para frenar una "policía del pensamiento" y una política McCartista de persecución (Podirier, 2018; Gill, 2018). Las galas llevan el debate a lo íntimo -argumenta Méndez (2018) - alejado de lo público, que da cabida a una variedad de circunstancias que difícilmente se pueden judicializar. De Paz (2018) agrega que es necesario frenar el señalamiento de culpable a los hombres por algo que no han hecho, o algo que pudo ser malinterpretado. La Otra palabra sugiere un debate abierto que ayude a comprender las dimensiones del acoso.

Los partidarios de la Otra palabra señalaron que se enriquece el debate al poner sobre la mesa varios puntos de vista y se matiza el tema del acoso. Se abre una discusión interesante -según Lucario (2018e), Méndez (2018), De Paz (2018) y Nebot (2018)- sobre las relaciones sexuales. Aunque se admitió que fue publicada en mal momento, estimula conversaciones francas que favorecen discutir ampliamente el acoso sin preconceptos y prejuicios (Tamés en Lucario, 2018e; Díaz, 2018). Quienes respaldaron el manifiesto, señalaron que su mayor logro fue discutir “¿qué se considera un crimen sexual?, ¿dónde está la frontera entre la seducción y la agresión sexual?” (García, 2018; Madrid, 2018), un espacio en el que reina la confusión, difícil de regular (Viennot, 2018), pero que nos debe ayudar a diferenciar entre el coqueteo y la violación (Andrade, 2018). Cómo plantea Sastre (en Gérard, 2018), las actrices estadounidenses se plantean un argumento distinto: las mujeres son pequeñas caperucitas rojas dispuestas a ser devoradas por el lobo, sin preguntarse sobre su complicidad al poner su sexualidad como moneda de cambio para obtener un papel cinematográfico.

\section{Reparación civil: códigos en disputa}

La disputa que se generó frente al \#Metoo y la Otra palabra sobre el acoso se definió por dos discursos en competencia que pese a sus diferencias se adhirieron a los códigos y significados civiles. Como sugieren Kivisto y Sciortino (2015), esto muestra que los conflictos sobre recursos y mecanismos de 
adscripción y exclusión son conflictos sobre su interpretación. Las posiciones en competencia manifestaron que el acoso debía denunciarse, las mujeres ser objeto de reparación civil y los victimarios castigados. Sin embargo, difirieron sobre el significado del acoso, la forma en cómo debe denunciarse y el rol de las instituciones. La diferencia se construyó a partir de las imputaciones que esgrimieron los comentarios a favor y en contra de \#Metoo y la Otra palabra. Dichas imputaciones se estructuraron en un conjunto de códigos binarios en los que se señaló el carácter puro e impuro, civil o anticivil, de ambas posiciones.

Las imputaciones negativas de clase contra la Otra palabra consideraron que su voz no era válida porque representaba a la burguesía francesa blanca, cerrada sobre si misma, ignorante de la vida del resto de las mujeres. ${ }^{7}$ En segundo lugar, se les acusó de ser una voz de otra época, donde la libertad sexual se consideró un medio para alcanzar la igualdad, soslayando que eso no trastoca las asimetrías de género. Las defensoras de la Otra palabra argumentaron contra \#Metoo su espíritu puritano que generaba mecanismos de control social y moral, muy en sintonía con el espíritu de los conservadores.

Se consideró que la Otra palabra se alejó de la religión para revitalizar la historia de liberalismo sexual francés que viene del siglo XVIII. Las voces a favor de las actrices francesas refrendaron la apuesta por la libertad, la pulsión sexual y la agencia erótica en ambos sexos, elementos constitutivos de carácter natural de las relaciones de género. Estas posiciones argumentaron que donde hay seducción y flirteo habrá confusión.

El supuesto carácter liberador de la Otra palabra fue interpretado por los defensores del \#Metoo como una defensa de las estructuras patriarcales que impiden que la seducción y flirteo sean libres, igualitarios y equitativos. La disputa por el significado de la seducción y el acoso estableció el perfil civil o anti-civil de la reparación hacia las mujeres. Quienes apoyaron el manifiesto francés señalaron que era necesario advertir que las mujeres no siempre juegan el papel de víctimas. En tanto que reconocen que las mujeres también seducen, llaman a relativizar el acoso. Este último debe ser juzgado considerando el proceso situacional en el que un hombre y una mujer se relacionan. Por su parte, quienes respaldaron a \#Metoo, insistieron en considerar el marco normativo que define el sentido social y legal del acoso.

La Otra palabra llama a juzgar cada caso de acoso en función de un contexto particular a fin de determinar la culpabilidad del acosador y la responsabilidad de la acosada, lo que despertó la crítica de quienes apoyaron al \#Metoo -estos últimos advirtieron que vulnera de entrada la reparación a la víctima. Finalmente, la disputa discutió el rol del cuerpo como determinante de lo femenino. Para la Otra palabra, el cuerpo aún y cuando haya sido objeto de violencia y humillación, no puede determinar el destino de las mujeres. Según esta posición, el acoso no resulta relevante para la libertad de espíritu. Los partidarios de \#Metoo acusan que este juicio ignora la relevancia del cuerpo en la vida de las mujeres y también de los hombres.

7- El movimiento \#Metoo también fue acusado de tener un sesgo de clase por Tarana Burke, quien en 2006 lanzó la frase Metoo por MySpace para generar la empatía entre las mujeres afroamericanas de áreas marginales estadounidenses que habían sido víctimas de abuso sexual. Burke señaló que el movimiento de las actrices estadounidenses dejó en el olvido el trabajo de las mujeres afroamericanas, las cuales no sólo buscaban la denuncia sino dialogar sobre el sentido de la agresión sexual. Si bien criticó al movimiento de las actrices de Hollywood, Burke reconoció el trabajo que estaban realizando. 


\section{Conclusiones}

La disputa que desató la Otra palabra frente a los posicionamientos de \#Metoo, dejó ver las diferentes interpretaciones sobre el acoso, su prevención y su atención. Los discursos en competencia permiten observar un conjunto definido de códigos binarios a escala global que buscaron interpretar la posición de las actrices estadounidenses y francesas. Esto permitió observar que existe una preocupación a escala internacional por el acoso y la violencia contra las mujeres, que se trata de significar para comprender y generar con ello los mecanismos de prevención y reparación a las víctimas. Existe también una inquietud por señalar a los victimarios, a qué mecanismos de poder y de relaciones responden, así como los motivos detrás de sus acciones. La pulsión sexual, el cuerpo, la agencia de hombres y mujeres se pone en consideración en estos debates. Los discursos en disputa imputaron al \#Metoo y a la Otra palabra de cualidades como el lenguaje, la raza, el sexo, la clase social y la etnia con el fin de atribuirles de vicios y virtudes cívicas. Además, se estableció un proceso de dicotomización moral geográfica y temporal de las representantes de cada movimiento: dependiendo de su ubicación geográfica y de adscripción generacional, se atribuyó cierta pureza o impureza moral en cada propuesta.

El debate en torno a la Otra palabra y \#Metoo expresa que ciertos conflictos y tensiones sociales se discuten a un nivel diferenciado, no exclusivamente local, sino global. Ciertamente, los comentarios frente a las posiciones en disputa no descartan las particularidades de los países europeos o latinoamericanos, pero existe la idea de que es posible construir -con sus particularidades- mecanismos de contención y reparación de los daños que produce el acoso. En este sentido, la disputa entre la Otra palabra y \#Metoo permite advertir la presencia de una esfera civil a escala global -un mundo de valores e instituciones que produce al mismo tiempo la capacidad de crítica social y la integración social-.

Una esfera civil con capacidad crítica para confrontar los procesos de dominación y exclusión social, pero no está exenta de tensiones, que se articula en conflictos sobre el sentido y la interpretación de la solidaridad, y de las instituciones capaces de producirla. Sin embargo, estas disputas no pueden generar instituciones regulativas a escala global: producir legislación, marcos jurídicos y normativos para enfrentar el acoso y la violencia, y sobre todo mecanismos de reparación civil. Con todo, la disputa que se ha analizado en este artículo muestra que hay un incipiente terreno de disputas globales que se dirimen a veces con mayor o menor éxito en espacios locales.

Si el debate sobre el acoso es global es porque existe una búsqueda por construir relaciones más equitativas e igualitarias entre hombres y mujeres. \#Metoo no ha sido un evento que se desvaneció en el tiempo, su espíritu se cristalizó hace poco en México -como en otros países de América Latina- con una serie de denuncias en el mundo artístico, político, académico y de la comunicación. La respuesta fue el apoyo y respaldo de miles de mujeres a quienes se atrevieron a denunciar el acoso. No obstante, esto desató igualmente una respuesta de hombres y mujeres que esgrimieron los argumentos de la Otra palabra. Esto debe llamar nuestra atención: las narrativas, así como las imputaciones sobre quienes participaron en el debate -pese a las particularidades del contexto nacional- mantuvieron pautas de interpretación y sentido similares. Analizar estas pautas globales y la forma en cómo se mediaron por los actores locales, es una labor que habría que llevar a cabo en el futuro. 


\section{Referencias}

Alexander, Jeffrey. 2006. The Civil Sphere. Oxford: Oxford University Press.

2013. The Dark Side of Modernity, London: Polity.

2015. Nine theses on the Civil Sphere. En Solidarity, Justice and Incorporation, editado por Peter Kivisto y Giuseppe Sciortino. Oxford: Oxford University Press, 172-190.

2016. Introduction: Journalism, democratic culture, and creative reconstruction. En

The Crisis of Journalism Reconsidered, editado por Jeffrey Alexander, Elizabeth Butler y Maria Luengo. Cambridge: Cambridge University Press, 1-30.

2017. The Drama of Social Life. Oxford: Oxford University Press.

Alexander, Jeffrey y Jason Mast. 2011. The cultural pragmatics of symbolic action. En Performance and Power, editado por Jeffrey Alexander. Cambridge: Cambridge University Press, 7-24.

Alexander, Jeffrey y Carlo Tognato. 2018. Introduction: For Democracy in Latin America. En The Civil Sphere in Latin America, editado por Jeffrey Alexander y Carlo Tognato. Cambridge: Cambridge University Press, 1-16.

Amo, Alberto. 2018. El despertar feminista en Francia. Rebelión. http://www.rebelion.org/noticia. php?id=237336 (16 de julio de 2019).

Andrade, Felipe. 2018. Un psiquiatra por favor. NTR Zacatecas, 29 de enero. http://ntrzacatecas. com/2018/01/29/relatos-de-la-historia-patria-153/ (15 de julio de 2019).

Arzuaga, Javier y Nelson Arteaga. 2017. Liturgia republicana y contra-performances: Protestas y pugnas en la investidura presidencial de 2012 en México. Revista Mexicana de Ciencias Políticas y Sociales Universidad Nacional Autónoma de México Nueva Época, 1 (229): 149-180.

Atwood, Margaret 2018. Am I a bad feminist? The Globe and Mail, 15 de enero. https://www.theglobeandmail.com/opinion/am-i-a-bad-feminist/article37591823/ (14 de julio de 2019).

Ayuso, Silvia. 2018. Las fronteras (¿y límites?) del feminismo. El País, 12 de enero. https:/elpais.com/ internacional/2018/01/12/actualidad/1515766831_721634.html (15 de julio de 2019).

Banet-Weiser, Sarah, Rosalind Gill y Catherine Rottenberg. 2019. Postfeminism, popular feminism and neoliberal feminism? Sarah Banet-Weiser, Rosalind Gill and Catherine Rottenberg in conversation. Feminist Theory, 0(0):1-22.

Belaich, Charlotte. 2018. La «séduction à la française» est-elle en danger? Libération, 11 de enero. https:// www.liberation.fr/france/2018/01/11/la-seduction-a-la-francaise-est-elle-en-danger_1621717 (13 de julio de 2019).

Beltrán, Rosa. 2018. El acoso sexual a primer plano. Vanguardia, 23 de enero. https://vanguardia.com. $\mathrm{mx} /$ articulo/el-acoso-sexual-primer-plano (13 de julio de 2019).

Benhabib, Seyla. 1992. Situating the self: Gender, community, and postmodernism in contemporary ethics. New York: Routledge.

Bernal-Triviño, Ana. 2018. No es puritanismo, es machismo. El Periódico, 10 de enero. https://www. elperiodico.com/es/opinion/20180110/no-es-puritanismo-es-machismo-articulo-ana-i-bernal-trivino-6543390 (13 de julio de 2019).

Berrin, Danielle. 2017. Should we forgive the men who assaulted us? The New York Times, 22 de diciembre. https://www.nytimes.com/2017/12/22/opinion/metoo-sexual-assault-orgiveness.html (13 de julio de 2019). 
Butler, Elizabeth y María Luengo. 2016. Conclusion: News innovation and enduring commitments. En The Crisis of Journalism Reconsidered, editado por Jeffrey Alexander, Elizabeth Butler y María Luengo. Cambridge: Cambridge University Press, 282-290.

Cadei, Emily. 2017. Few in Washington are saying \#MeToo. California congresswoman wants to change that. En Miami Herald, 25 de octubre. https://web.archive.org/web/20171026054331/http:/www.miamiherald.com/news/politics-government/article180767911.html (13 de julio de 2019).

Carlson, Gretchen. 2017. How to encourage more women to report sexual harassment. The New York Times, 10 de octubre. https://www.nytimes.com/2017/10/10/opinion/women-reporting-sexual-harassment.html (13 de julio de 2019).

Casanova, Argentina. 2018. Importunar no es derecho. Cima Noticias, 26 de enero. http://www.cimacnoticias.com.mx/noticia/importunar-no-es-derecho (14 de julio de 2019).

Clark-Parsons, Rosemary. 2019. "I see you, I believe you, I stand with you": \#MeToo and the performance of networked feminist visibility. Feminist Media Studies, 19: 1-19. https://doi.org/10.1080/14680777.20 19.1628797

Coll, Alejandra. 2018. ¿Seducción torpe o acoso? La Silla Llena, 16 de enero. http://lasillavacia.com/sillallena/red-de-las-mujeres/historia/seduccion-torpe-o-acoso-64214 (14 de julio de 2019).

Collado, Alejandra. 2018. Exageradas, persignadas y también putas, por si acaso. La Silla Rota, 27 de enero. https:/lasillarota.com/opinion/columnas/exageradas-persignadas-y-tambien-putas-por-si-acaso/202271 (13 de julio de 2019).

Collins, Lauren. 2018. Why did Catherine Deneuve and other prominent french women denounce \#MeToo? The New Yorker, 10 de enro. https:/www.newyorker.com/news/daily-comment/why-did-catherine-deneuve-and-other-prominent-frenchwomen-denounce-metoo (15 de julio de 2019).

Cruz, Pedro. 2018. Atwood VS. \#metoo: contra el triunfo de la justicia populista. La Razón, 17 de enero. https://www.larazon.es/cultura/atwood-vs-metoo-contra-el-triunfo-de-la-justicia-populistaNG17449510 (13 de julio de 2019).

D’Zurilla, Christie. 2017. In saying \#MeToo, Alyssa Milano pushes awareness campaign about sexual assault and harassment. Los Angeles Times, 16 de octubre. https://web.archive.org/web/20171017075641/ http:/www.latimes.com/entertainment/la-et-entertainment-news-updates-metoo-campaign-me-tooalyssa-milano-1508173882-tmlstory.html (13 de julio de 2019).

De Benedictis, Sara, Shani Orgad y Catherine Rottenberg. 2019. \#MeToo, popular feminism and the news: A content analysis of UK newspaper coverage. European Journal of Cultural Studies, 00(0): 1-21.

De la Barreda, Luis. 2018. Abuso versus seducción. Excélsior, 25 de enero. http://www.excelsior.com.mx/ opinion/Luis-de-la-barreda-Solórzano/2018/01/25/1215904 (15 de julio de 2019).

De la Peña, Angélica. 2018. \#MeToo o no hay tanta bronca. El Sol de México. https://www.elsoldemexico. com.mx/análisis/metoo-o-nohaytantabronca-562069.html (14 de julio de 2019).

De Paz, Maribel. 2018. MeToo: analizando una polémica que remece Hollywood. El Comercio, 23 de enero. https://elcomercio.pe/luces/impreso-metoo-analizando-polemica-remece-hollywood-noticia-491123 (14 de julio de 2019).

Di Bennardo, Rebecca. 2018. Ideal Victims and Monstrous Offenders: How the News Media Represent Sexual Predators. Socius, 4: 1-20. 
Díaz, Sabrina. 2018. Debate: las argentinas, más cerca de \#Metoo que de las francesas. Clarín, 20 de enero. https://www.clarin.com/sociedad/debate-argentinas-cerca-metoo-francesas_0_ByQds4ZBG.html (13 de julio de 2019).

Douglas, Mary. 1979. Purity and danger: An analysis of concepts of pollution and taboo. Londres: Routledge and Kegan Paul.

Downing, Lisa. 2018. The body politic: Gender, the right wing and 'identity category violations'. French Cultural Studies, 29(4):367-377.

Dresser, Denise. 2018. ¿Torquemadas? El Siglo de Durango, 15 de enero. https://www.elsiglodedurango. com.mx/noticia/933603.torquemadas.html (13 de julio de 2019).

Dudda, Ricardo. 2018. Contra la hegemonía anglosajona. El País, 1 de febrero. https://elpais.com/elpais/2018/02/01/opinion/1517508501_062344.html (14 de julio de 2019).

Dunham, Lena. 2017. Lena Dunham: Harvey Weinstein and the Silence of the Men. The New York Times, 9 de octubre. https://www.nytimes.com/2017/10/09/opinion/harvey-weinstein-lena-dunhamsilence-.html (13 de julio de 2019).

Earl, Jennifer, Andrew Martin, John McCarthy y Sarah Soule. 2004. The use of newspaper data in the study of collective action. Annual Review of Sociology, 30:65-80.

Estremadoiro, Winston. 2018. Extremos en el tema del acoso sexual. Los Tiempos, 19 de enero. http:// www.lostiempos.com/actualidad/opinion/20180119/columna/extremos-tema-del-acoso-sexual (14 de julio de 2019).

Europa Press. 2018. Femen defiende el 'Me too' frente a mujeres como las artistas francesas, que "hacen el juego al patriarcado". El Periódico, 11 de enero. https://www.elperiodico.com/es/ocio-y-cultu$\mathrm{ra} / 20180111 /$ femen-defiende-el-me-too-frente-a-mujeres-como-las-artistas-francesas-que-hacen-eljuego-al-patriarcado-6545583 (16 de julio de 2019).

Eyerman, Ron y Andrew Jamison. 1990 Social Movements: A cognitive Approach. London: Polity. Faur, Eleonor. 2018. Abuso sexual. Parar la mano. Anfibia. http://www.revistaanfibia.com/ensayo/pararla-mano-2/ (14 de julio de 2019).

Félix, Paola. 2018. Del puritanismo a la realidad. El Universal, 18 de enero. Disponible en: http://www. eluniversal.com.mx/articulo/paola-felix-diaz/nación/del-puritanismo-la-realidad (15 de julio de 2019). Fernández, Laura. 2018. Goce versus puritanismo, ¿todavía? Clarín, 26 de enero. https://www.clarin. com/revista-enie/ideas/goce-versus-puritanismo-todavia_0_BkzGAWYHM.html (14 de julio de 2019). Ferreyra, Marta. 2018. Crecer después de la tormenta. La Razón, 2 de febrero. https://www.razon.com. mx/crecer-después-la-tormenta/ (14 de julio de 2019).

Filipovic, Jill. 2017. The Bad News on 'Good' Girls. The New York Times, 24 de noviembre. https://www. nytimes.com/2017/11/24/opinion/sunday/girls-parents-boys-gender.html (13 de julio de 2019).

France Télévisions. 2018. TRIBUNE. "Les porcs et leurs allié.e.s ont raison de s'inquiéter": Caroline De Haas et des militantes féministes répondent à la tribune publiée dans "Le Monde". Franceinfo, 10 de enero. https://www.francetvinfo.fr/societe/droits-des-femmes/tribune-les-porcs-et-leurs-allie-e-s-ontraison-de-sinquieter-caroline-de-haas-et-des-militantes-feministes-repondent-a-la-tribune-publieedans-le-monde_2553497.html (13 de julio de 2019).

Fraser, Nancy. 1992. Rethinking the public sphere: A contribution to of actually existing democracy." En Habermas and the Public Sphere, editado por Craig Calhoun. Cambridge: MIT, 109-142. 
García, Beatriz. 2018. ¿De qué hablamos cuando hablamos de acoso? Mujer Hoy, 28 de enero. http:// www.mujerhoy.com/vivir/sexo-pareja/201801/28/acoso-sexual-movimiento-metoo-20180125181212. html (el 13 de julio de 2019).

Gérard, Aline. 2018. Débat: faut-il défendre «la liberté d’importuner»? Le Parisen, 11 de enero. http:// www.leparisien.fr/societe/debat-faut-il-defendre-la-liberte-d-importuner-11-01-2018-7494240.php (13 de julio de 2019).

Gersen, Jeannie. 2017. The transformation of sexual-harassment law will be double-faced. The New Yorker, 20 de diciembre. https://www.newyorker.com/news/news-desk/the-transformation-of-sexualharassment-law-will-be-double-faced (15 de julio de 2019).

Gill, Charlotte. 2018. This McCarthyite campaign against men goes too far. The Times, 12 de enero. https://www.thetimes.co.uk/article/this-mccarthyite-campaign-against-men-goes-too-far-dnsphx9s3 (15 de julio de 2019).

González, Ariel. 2018. Del acoso al puritanismo. Milenio, 13 de enero. http://www.milenio.com/firmas/ ariel_gonzalez_jimenez/acoso-puritanismo-feminismo-metoo-hollywood-globos_oro-catherine_deneuve_18_1102869742.html (14 de julio de 2019).

Grenier, Robin. 2019. Speaking Truth to Power Through Social Movements and Learning. Advances in Developing Human Resources, 21(2): 143-149.

Gupta, Akhil. 2015. Fronteras borrosas: el discurso de la corrupción, la cultura de la política y el estado imaginado. En Antropología del Estado, editado por Philip Abrams, Akhil Gupta y Timothy Mitchell. México: Fondo de Cultura Económica, 71-144.

Hasunuma, Linda y Shin Ki-young. 2019. \#MeToo in Japan and South Korea: \#WeToo, \#WithYou. Journal of Women, Politics \& Policy, 40 ((1):97-111.

Hubbard, Shanita. 2017. Russell Simmons, R. Kelly, and Why Black Women Can't Say \#MeToo. The New York Times, 15 de diciembre. https://www.nytimes.com/2017/12/15/opinion/russell-simmons-blackwomen-metoo.html (13 de julio de 2019).

Infobae. 2018. El manifiesto completo de las intelectuales francesas contra el \#MeToo. 9 de enero de 2018. https://www.infobae.com/america/mundo/2018/01/09/el-manifiesto-completo-de-las-intelectuales-francesas-contra-el-metoo/ (11 de enero de 2018)

Johansson, Håkan y Gabriella Scaramuzzino. 2019. The logics of digital advocacy: Between acts of political influence and presence. New Media \& Society, 21(7): 1528-1545.

Kislinger, Luisa. 2018. Cien francesas dijeron... Efecto Cocuyo, 24 de enero. http://efectococuyo.com/ opinion/cien-francesas-dijeron/ (13 de julio de 2019).

Kivisto, Peter y Giuseppe Sciortino. 2015. Introduction: Thinking The Civil Sphere. En Solidarity, Justice and Incorporation, editado por Peter Kivisto y Giuseppe Sciortino. Oxford: Oxford University Press, $1-30$.

Lamas, Marta. 2018. Acoso. ¿Denuncia legítima o victimización? México: FCE.

La Nación. 2018. Globos de Oro 2018: el discurso completo de Oprah Winfrey. La Nación, 8 de enero. https://www.lanacion.com.ar/espectaculos/lee-el-discurso-completo-de-oprah-winfrey-en-los-globosde-oro-nid2098718 (13 de julio de 2019). 
La Voz de Galicia. 2018. La frontera entre el flirteo y el acoso sexual. La Voz de Galicia, 14 de enero. https://www.lavozdegalicia.es/noticia/sociedad/2018/01/14/frontera-flirteo-acososexual/0003_201801G14P25991.htm (13 de julio de 2019).

Latapí, Alejandra. 2018. ¿De brujas a inquisidoras? Milenio, 18 de enero. https://www.milenio.com/opinion/alejandra-latapi/columna-alejandra-latapi/de-brujas-a-inquisidoras (13 de julio de 2019).

Lehoux, Valérie. 2018. Laure Adler: "Pourquoi je n’ai pas signé la tribune sur 'la liberté d'importuner'. Télérama, 13 de enero. https://www.telerama.fr/monde/laure-adler-pourquoi-je-nai-pas-signe-la-tribune-sur-la-liberte-dimportuner,n5437559.php (13 de julio de 2019).

Lévy-Willard, Annette. 2018. «Nous voulons être importunées sexuellement!». Libération, 11 de enero. http://annette.blogs.liberation.fr/2018/01/11/xxx/ (13 de julio de 2019).

Lozada, Luis. 2018. Ni tanto que queme al Santo, ni tanto que no lo alumbre. Milenio, 14 de enero. http://www.milenio.com/firmas/luis_lozada_leon/le_monde-acoso_sexual-metoo-catherine_deneuvedonald_trump_18_1103469691.html (15 de julio de 2019).

Lucario, Sandra. 2018a. 'Decepcionante', 'machista' pero también 'entendible' y 'debatible'... Mexicanas responden al manifiesto feminista francés. The Huffington Post, 10 de enero. http://www.huffingtonpost.com.mx/2018/01/10/decepcionante-machista-pero-tambien-entendible-y-debatible-mexicanasresponden-al-manifiesto-feminista-frances_a_23330262/ (14 de julio de 2019).

2018b. Fernanda Solórzano: 'Contiene afirmaciones que pueden ser problemáticas'. The Huffington Post, 12 de enero. https://www.huffingtonpost.com.mx/2018/01/12/fernanda-solorzano-contiene-afirmaciones-que-pueden-ser-problematicas_a_23332098/(13 de julio de 2019).

2018c. Karla Michelle Salas: 'El abuso de poder no es natural, la violencia no es natural. The Huffington Post, 14 de enero. http://www.huffingtonpost.com.mx/2018/01/14/karla-michellesalas-el-abuso-de-poder-no-es-natural-la-violencia-no-es-natural_a_23332155/ (14 de julio de 2019).

2018d. Martha Tagle: "Representa una valiosa oportunidad para seguir hablando de la problemática de acoso y hostigamiento sexual". The Huffington Post, 14 de enero. https://www.huffingtonpost.com.mx/2018/01/14/martha-tagle-representa-una-valiosa-oportunidad-para-seguir-hablandode-la-problematica-del-acoso-y-hostigamiento-sexual_a_23332281/ (14 de julio de 2019).

2018e. Regina Tamés: "Las mujeres debemos atesorar y cuidar las libertades sexuales que hemos logrado". The Huffington Post, 14 de enero. http://www.huffingtonpost.com. $\mathrm{mx} / 2018 / 01 / 14 /$ regina-tames-las-mujeres-debemos-atesorar-y-cuidar-las-libertades-sexuales-que-hemos-logrado_a_23332235/ (14 de julio de 2019).

2018f. Tamara de Anda: 'Las feministas francesas que firmaron el manifiesto no ven más allá de sus narices'. The Huffington Post, 14 de enero. http://www.huffingtonpost.com. $\mathrm{mx} / 2018 / 01 / 14 /$ tamara-de-anda-las-feministas-francesas-que-firmaron-el-manifiesto-no-ven-mas-alla-de-sus-narices_a_23332146/(13 de julio de 2019).

2018g. Ximena Andión: “Es riesgoso pensar que cualquier galantería o seducción es acoso". The Huffington Post, 12 de enero. http://www.huffingtonpost.com.mx/2018/01/12/fernanda-solorzanocontiene-afirmaciones-que-pueden-ser-problematicas_a_23332098/(consultado el 14 de julio de 2019).

Luengo, Maria. 2018. Shaping solidarity in Argentina: The power of the civil sphere in repairing violence against women. En The Civil Sphere in Latin America, editado por Jeffrey Alexander y Carlo Tognato. Cambridge: Cambridge University Press, 39-65. 
Madrid, Alberto. 2018. Guerra abierta contra el piropo: el tuit que arrasa en Twitter. Los 40, 16 de enero. http://los40.com/los40/2018/01/16/bigbang/1516116247_222282.html (15 de julio de 2019).

Marco, José. 2018. Pánico moral. José María Marco, 13 de enero. https://www.josemariamarco.com/ideas-ideas/panico-moral/ (14 de julio de 2019).

Martínez, León. 2018. Apuntes sobre la discusión alrededor del movimiento \#MeToo. El Economista, 13 de enero. https://www.eleconomista.com.mx/política/Apuntes-sobre-la-discusion-alrededor-del-movimiento-MeToo-20180113-0001.html (14 de julio de 2019).

Mascia, Carla. 2018. La guerra feminista se libra en los medios. El País, 15 de enero. https:/elpais.com/ elpais/2018/01/12/opinion/1515788449_947888.html (13 de julio de 2019).

McCarthy, John, Clark McPhail, y Jackie Smith. 1996. Images of protest: Dimensions of selection bias in media coverage of Washington demonstrations, 1982 and 1991. American sociological review, 61(3): 478-499.

McKinney, Claire. 2019. Sexual Coercion, Gender Construction, and Responsibility for Freedom: A Beauvoirian Account of Me Too. Journal of Women, Politics \& Policy, 40(1): 75-96.

Melgar, Lucía. 2018. El acoso no está a debate II/II. El Economista, 22 de enero. https://www.eleconomista.com.mx/opinion/El-acoso-no-esta-a-debate--20180122-0046.html (14 de julio de 2019).

Mendes, Kaitlynn, Jessalynn Keller y Jessica Ringrose. 2019. Digitized narratives of sexual violence: Making sexual violence felt and known through digital disclosures. New Media \& Society, 21(6):1290-1310. Méndez, Jarumy. 2018. INDICIO ESMERALDA: \#MeToo el hombre como enemigo. El Oriente, 14 de enero. http://www.eloriente.net/home/2018/01/14/indicio-esmeralda-metoo/ (15 de julio de 2019).

Merino, Olga. 2018. Las francesas y el \#MeToo. El Periódico, 20 de enero. https://www.elperiodico.com/ es/opinion/20180120/las-francesas-y-el-metoo-articulo-olga-merino-acoso-sexual-6566279 (13 de julio de 2019).

Merkin, Daphne. 2018. Publicly, We Say \#MeToo. Privately, We Have Misgivings. The New York Times, 5 de enero. https:/www.nytimes.com/2018/01/05/opinion/golden-globes-metoo.html (13 de julio de 2019). Milenio. 2018. \#MeToo va contra acoso, no contra coqueteo: especialistas. Milenio, 11 de enero. Disponible en: http://www.milenio.com/tendencias/marta-lamas-catalina-ruiz-navarro-me-too-francesasacoso-sexual_0_1101490031.html (14 de julio de 2019).

Morejón, Rosario. 2018. Otras mujeres con voz: veracidad, sexo y libertad. Diario Vasco, 17 de enero. https://www.diariovasco.com/opinion/mujeres-veracidad-sexo-20180117212412-nt.html (15 de julio de 2019).

Munker, Barbara. 2018. El movimiento \#MeToo llega a Sundance: "Ahora, el papel de los hombres es escuchar", dice Redford. El Mundo, 19 de enero. http://www.elmundo.es/cultura/cine/2018/01/19/5a61e 317e2704e91448b462d.html (13 de julio de 2019).

Mural de Negro. 2018. Lydia Cacho: 'La galantería y la seducción implican un juego'. Mural de Negro, 15 de enero. http://muraldegenero.com/lydia-cacho-la-galanteria-la-seduccion-implican-juego/ (16 de julio de 2019).

Nebot, Marta 2018. ¿Lucha en el barro entre feministas? No, gracias. Público, 11 de enero. http://blogs. publico.es/otrasmiradas/12312/lucha-en-el-barro-entre-feministas-no-gracias/ (14 de julio de 2019).

Neill, Ushma. 2017. When Scientists Say, “Me, Too". Scientific American, 18 de octubre. https://web. archive.org/web/20171026054215/https:/blogs.scientificamerican.com/voices/when-scientists-say-metoo/ (13 de julio de 2019). 
Ohlheiser, Abby. 2017. The woman behind 'Me Too' knew the power of the phrase when she created it - 10 years ago. Los Angeles Times, 19 de octubre. https://web.archive.org/web/20171019201825/https:/ www.washingtonpost.com/news/the-intersect/wp/2017/10/19/the-woman-behind-me-too-knew-thepower-of-the-phrase-when-she-created-it-10-years-ago/?utm_term=.bc28f8815787 (13 de julio de 2019). Olavarría, Erika. 2018. Los hombres franceses alzan la voz a favor de \#MeToo. France 24, 31 de enero. https://www.france24.com/es/20180131-hombres-franceses-metoo (13 de julio de 2019).

Ortiz, David, Daniel Myers, Eugene Walls y Maria-Elena Diaz. 2005. Where do we stand with newspaper data? Mobilization: An International Quarterly, 10(3): 397-419.

Pateman, Carole. 1988. "The fraternal social contract." En Civil Society and the State: New European Perspectives, editado por John Keane. London: Verso, 101-128.

Peker, Luciana. 2018. Ni puritanas, ni puras víctimas. Página 12, 19 de enero. https://www.pagina12.com. ar/90035-ni-puritanas-ni-puras-victimas (13 de julio de 2019).

Pfister, Damien y Yang, Misti. 2018. Five theses on technoliberalism and the networked public sphere. Communication and the Public, 3(3):247-262.

Podirier, Agnès. 2018. Deneuve y el feminismo de las francesas. El País, 19 de enero. https://elpais.com/ elpais/2018/01/19/opinion/1516380216_568037.html (14 de julio de 2019).

Priego-Broca, María. 2018. ¿Cómo marchar juntas? La Silla Rota. https://lasillarota.com/opini\%C3\%B3n/ columnas/como-marchar-juntas/200100 (13 de julio de 2019).

Raulin, Nathalie, Catherine Mallaval y Laure Bretton. 2018. Marlène Schiappa: un ovni pour la galaxie féministe". Libération, 20 de marzo. https://www.liberation.fr/politiques/2018/03/20/marlene-schiappaun-ovni-pour-la-galaxie-feministe_1637682 (16 de julio de 2019).

Razer, Helen. 2018. The 'black gown' Golden Globes 'inspired' no one but the empty headed stars in them. Daily Review, 11 de octubre. https://dailyreview.com.au/author/helen-razer/ (14 de julio de 2019). Revuelta, Laura. 2018. La revolución cultural y social del \#MeToo. ABC, 28 de enero. http://www.abc.es/ cultura/cultural/abci-revolucion-cultural-y-social-metoo-201801280121_noticia.html (13 de julio de 2019). Río, Manuel. 2008. Usos y abusos de la prensa como fuente de datos sobre las acciones colectivas. Revista de Metodología de Ciencias Sociales, 16(2): 59-84.

Rodríguez, Aloma. 2018. \#MeToo: Declaración de guerra. Letras Libres, 26 de enero. https://www.letraslibres.com/espana-mexico/cultura/metoo-declaracion-guerra (16 de julio de 2019).

RTBF. 2018. Anne Morelli: "Les femmes paraissent toujours victimes, mais nous sommes aussi dragueuses". RTBF. 11 de enero. https://www.rtbf.be/info/societe/detail_anne-morelli-les-femmes-paraissent-toujours-victimes-mais-nous-sommes-aussi-dragueuses?id=9808351 (13 de julio de 2019).

Salvador, Ángeles. 2018. Norteamericanas vs. francesas: historia de una vieja rivalidad que volvió tras las denuncias de acoso sexual en Hollywood. Clarín, 13 de enero. https://www.clarin.com/opinion/marilynvs-brigitte-norteamericanas-francesas-volvieron-ring-fenomeno-metoo_0_Sk3f6CPNM.html (14 de julio de 2019).

Sánchez-Mellado, Luz. 2018. Paz, hermanas. El País, 10 de enero. https://elpais.com/elpais/2018/01/10/ opinion/1515602350_010954.html (13 de julio de 2019).

Sénac, Réjane. 2018. 'L'enjeu est que chacun.e puisse s'imaginer comme un.e semblable'. Le Noveau Magazine, 12 de enero. https://www.nouveau-magazine-litteraire.com/idees/-lenjeu-est-que-chacun-puissesimaginer-comme-un-semblable- (16 de julio de 2019). 
Stephens, Bret. 2017. When \#MeToo Goes Too Far. The New York Times, 20 de diciembre. https://www. nytimes.com/2017/12/20/opinion/metoo-damon-too-far.html (13 de julio de 2019).

Thomas, Florence. 2018. Desenredar el salpicón. El Tiempo, 24 de enero. https://www.eltiempo.com/ opinion/columnistas/florence-thomas/desenredar-el-salpicon-el-debate-del-acoso-sexual-174388 (13 de julio de 2019).

Toranian, Valérie. 2018. Libération sexuelle: une autre parole est-elle possible? Revue Des Deux Mondes, 15 de enero. https://www.revuedesdeuxmondes.fr/liberation-sexuelle-parole-possible/ (13 de julio de 2019). Torreblanca, Carolina, Mónica Meltis, María Zilli, Jimena Soria, Daniela Tejas, Daniela Philipson y Cristina MacGregor. 2018. El feminismo no es el nuevo puritanismo. Animal Político, 19 de enero. https:// www.animalpolitico.com/blogueros-blog-invitado/2018/01/19/feminismo-no-nuevo-puritanismo/ (13 de julio de 2019).

Viennot, Bérengère. 2018. Pourquoi jai signé la tribune «Des femmes libèrent une autre parole». Slate, 15 de enero. https://www.slate.fr/story/156254/debat-feminisme-pourquoi-tribune-femmes-autre-parole (13 de julio de 2019).

Weiss, Bari. 2018. Aziz Ansari Is Guilty. Of Not Being a Mind Reader. The New York Times, 15 de enero. https://www.nytimes.com/2018/01/15/opinion/aziz-ansari-babe-sexual-harassment.html (13 de julio de 2019).

West, Lindy. 2018. Aziz, We Tried to Warn You. The New York Times, 17 de enero. https://www.nytimes. com/2018/01/17/opinion/aziz-ansari-metoo-sex.html (13 de julio de 2019).

Wiener, Gabriela. 2018a. 'El manifiesto de las francesas es una venganza del patriarcado.' La República, 20 de enero. http://larepublica.pe/domingo/1173741-el-manifiesto-de-las-francesas-es-una-venganza-delpatriarcado (13 de julio de 2019).

2018b. Yo te acoso, 'moi non plus'. The New York Times, 13 de enero. https://www. nytimes.com/es/2018/01/13/yo-te-acoso-moi-non-plus/ (13 de julio de 2019).

Zárate, Liz. 2018. \#MeToo merece ir más allá de denuncias mediatizadas. Las 2 Orillas. https://www. las2orillas.co/metoo-merece-ir-mas-allá-de-denuncias-mediatizadas/ (14 de julio de 2019). 